\title{
O que estou lendo agora?
}

Após ficar fascinado por vários anos pelas produções que assisti de Romeo Castellucci e da Societas Raffaello Sanzio, e especialmente por sua recente Hyperion, a qual assisti em Berlim, em maio deste ano (2013), adquiri o livro escrito por Gabriella Giannachi e Nick Kaye, Staging the Post-Avant-Garde, publicado pela Peter Lang em 2002, que situa a Societas no contexto teatral ao discutir a performance experimental italiana a partir de 1970. Para além de Castellucci, tive algum contato com o trabalho experimental de Mario Martone e Giorgio Corsetti, havendo um capítulo do livro dedicado a cada um deles, mas eu tinha pouco conhecimento da trajetória completa de suas carreiras e de que forma os dois, ou mesmo Castellucci, se encaixavam na prática teatral italiana recente.

Um capítulo introdutório oferece o background para a obra ao discutir brevemente as ideias e a prática das gerações anteriores de diretores experimentais italianos que, segundo os autores, representam a vanguarda italiana moderna - Carmelo Bene, Carlo Quartucci, Leo de Bernardinis, Carlo Cecchi e Memè Perlini. O teatro que surge a partir desta experimentação, e que é a maior preocupação do livro, se relaciona de forma impressionante com o trabalho experimental da atualidade nos Estados Unidos e, particularmente, em partes da Europa, particularmente, e parece-me, em seu interesse na abordagem multimídia da cena e sua preocupação com a mistura do real com o teatral. O último capítulo, que ainda não li, pesquisa a nova geração que emergiu nos anos 1990, particularmente os grupos Motus e Masque. Trabalhos individuais são analisados, com atenção particular ao que revelam sobre a estética, as preocupações formais e as premissas dos artistas que produzem as obras. Seria útil se o livro tivesse relacionado um pouquinho mais o trabalho que investiga àquele dos artistas atuais em outros países - na parte que li apenas Robert Wilson é mencionado dentre as muitas 
possibilidades - mas, mesmo com sua orientação ampla e exclusivamente italiana, eu estou achando este estudo extremamente esclarecedor.

Fora alguns estudos focados na tradição javanesa wayang (teatro de sombras feito com marionetes), a vasta e culturalmente complexa região situada entre a Austrália e a Tailândia quase não recebeu atenção por parte dos historiadores ocidentais do teatro, conforme descobri recentemente quando dei um seminário sobre o teatro do mundo árabe/islâmico. Descobri, então, que enquanto esta parte do mundo era negligenciada como um todo por tais historiadores (normalmente com a desculpa mal informada e incorreta de que o Islã não tolera o teatro), a Indonésia, de longe o maior país do mundo islâmico, havia recebido menos atenção do que os estados islâmicos do Oriente Médio ou do norte da África. Fiquei, portanto, extremamente satisfeito por encontrar o livro muito bem informado de Evan Winet, Indonesian Postcolonial Theatre, de 2010, que ofereceu pela primeira vez, em inglês, um olhar detalhado sobre aquele assunto. A Indonésia é um país vasto, por este motivo, Winet, compreensivelmente, se focou sobre o centro cultural e político da Indonésia, Java. Fiquei muito satisfeito este ano por descobrir outro estudo recente que lança luzes adicionais sobre esta parte muito negligenciada do mundo do teatro moderno. Trata-se de Fears of Loss, Tears of Joy: Raun Raun Theatre and Its Role in the Construction of a National Culture in Papua New Guinea, de Greg Murphy (publicado pela University of Papua New Guinea Press, em 2010). Embora o foco deste livro seja muito mais estreito do que o de Winet, preocupando-se com a história de uma única companhia chave durante os anos 1970 e 80, o livro lida com muitos dos mesmos assuntos abordados por Winet, que de fato são centrais para os teatros pós-coloniais ao redor do mundo: as pressões do nacionalismo, a luta entre a organização teatral centralizada ou descentralizada, a busca pelas audiências, a utilização de formas indígenas e as inevitáveis negociações dos experimentos híbridos resultantes disso. Papua Nova Guiné é ao mesmo tempo muito próxima e muito distinta da Indonésia. Ela é primariamente composta pela metade de uma das maiores ilhas do mundo, a outra metade sendo parte da Indonésia, mas enquanto a Indonésia é muçulmana, Papua Nova Guiné é quase inteiramente cristã. A história colonial também é diferente: a parte indonésia da ilha tendo sido uma colônia holandesa, enquanto a outra parte fora dividida entre as colônias alemãs e inglesas (e posteriormente australianas). Estas diferenças históricas e religiosas resultaram em culturas teatrais contemporâneas bem diferentes nas duas partes da mesma ilha (em escala muito menor, poderia-se pensar no Haiti e na Repú- 
blica Dominicana). Estas diferenças por si só são bastante esclarecedoras e é muito encorajador ver o teatro desta parte do mundo começar a ganhar atenção de estudiosos.

Em 1991, The Feminist Spectator as Critic de Jill Dolan foi um dos primeiros livros no campo emergente dos estudos feministas do teatro, e desde aquela época, em seus livros subsequentes e em seu serviço para as principais organizações profissionais dos Estados Unidos, Dolan se tornou uma figura importante na erudição do teatro moderno. Desde 2005 ela tem editado regularmente um blogue muito admirado, The Feminist Spectator, no qual ela coloca em ação suas habilidades de crítica em análises profundas e divertidas sobre as peças e filmes em cartaz. Em 2011 este blogue recebeu o prestigiado prêmio Gerorge Jean Nathan de crítica dramática, e foi o primeiro blogue na história a receber tal honraria. Agora uma seleção destes ensaios, editada por Dolan, aparece em forma de livro sob o título The Feminist Spectator in Action, publicado em 2013 pela Palgrave Macmillan. Embora eu já tenha encontrado algumas destas análises no blogue de Dolan, sua aparição em uma coletânea, organizada tematicamente pela autora, incrementa com distinção seu valor e sua contribuição.

Por fim, acabo de começar a ler outra coletânea de ensaios, neste caso, de diversos autores, reunidos por outra teórica pioneira do teatro moderno, Josette Féral. É Pratiques performatives; Body Remix, publicado em 2012 pelas Presses de l'Université de Québec. Os dezessete variados ensaios que compõem esta coletânea preocupam-se, em sua maioria, com a questão da presença e do corpo, um interesse central dos estudos do teatro contemporâneo, especialmente à luz da utilização sempre crescente de imagens digitais e virtuais no teatro. Para mim, um dos maiores atrativos desta coletânea, à parte a importância de seu assunto central, é a exposição do trabalho de um grupo internacional de estudiosos (do Canadá, Itália, França, Alemanha e Suíça) que não fazem parte da tradição anglo-saxônica. Os estudos teatrais acadêmicos nos Estados Unidos e na Inglaterra tendem a ser monolíngue, quase nunca em diálogo com os estudos de qualquer outro lugar, a menos e até que tal estudo seja traduzido para o inglês. O resultado é um discurso enfraquecido que se torna mais e mais problemático conforme o mundo fica mais e mais conectado. Eu, portanto, penso que esta coletânea é bem-vinda não apenas para que se tome contato com numerosos colegas acadêmicos - em sua maioria desconhecidos para mim até então - mas também para que se tenha o prazer e o desafio de ouvir questões e preocupações que me são familiares dentro da tradição em língua inglesa, abordadas de maneiras novas e estimulantes. 


\section{Referências Bibliográficas}

DOLAN, Jill. The feminist spectator as critic. Ann Arbor: University of Michigan Press, 2012.

The Feminist Spectator in Action: Feminist Criticism for the Stage and Screen. Basingstoke: Palgrave Macmillan, 2013.

FÉRAL, Josette. Body remix. Quebec: Presses De l'Université du Québec, 2012.

GIANNACHI, Gabriella; KAYE, Nick. Staging the post-avant-garde. Broadway: P. Lang, 2002.

MURPHY, Greg. Fears of Loss Tears of Joy: Raun Raun Theatre and Its Role in the Construction of a National Culture in Papua New Guinea. Port Moresby: University of Papua New Guinea Press and Bookshop, 2010.

WINET, Evan Darwin. Indonesian postcolonial theatre: spectral genealogies and absent faces. Basingstoke: Palgrave Macmillan, 2010. 